Article

\title{
School-University Links for Evidence-Informed Practice
}

\author{
Tim Cain 1 (D) \\ Faculty of Education, Edge Hill University, Ormskirk L39 4QP, UK; tim.cain@edgehill.ac.uk
}

Received: 14 February 2019; Accepted: 28 April 2019; Published: 3 May 2019

\begin{abstract}
A range of studies has identified barriers to evidence-informed practice in schools, many of which recommend school-university links as a means for removing these barriers. In England, public policy also promotes school-university partnerships, which expects these to have benefits for both schools and universities. Secondary analysis of data from five qualitative research projects reveals that school-university links are formed around activities, including postgraduate degrees, research projects and evaluations, Teacher Research projects, research dissemination conferences and seminars, Initial Teacher Education, research-informed Continuous Professional Development (CPD), and bidding for funding. Although, superficially, these activities might seem to enable more and better, evidence-informed practice in schools, school-university links are founded on activities that are declining, those that are short-term, and those that heavily rely on the enthusiasm of a few people. This paper concludes by offering suggestions for improving school-university links, so as to enable research to better inform practice.
\end{abstract}

Keywords: school-university partnerships; research-practice gap; evidence-informed teaching; research utilization; knowledge mobilization

\section{Introduction}

Local and national governments and their education ministries in various countries around the world are promoting the use of research evidence by teachers. Such promotion can be seen to have a rhetorical aspect, because it effectively shifts responsibility for educational successes and failures away from governments and towards schools and universities. In a political climate of austerity, educational failure then becomes less a matter of inadequate funding and more a matter of schools that are failing to do 'what works' with consequences, as Hordern points out in this Issue, for conceptualizations both of research traditions and teaching practice.

However, the promotion of evidence-informed practice is not merely rhetorical; it also involves practical measures. In England, practical measures have been employed to 'push', 'pull', and 'mediate' research into practice [1]. 'Push' mechanisms include the periodic Research Excellence Framework (the 'REF'), through which United Kingdom (UK) universities are required to account for the 'impact' that their research has on, 'the economy, society, culture, public policy or services ... beyond academia' [2]. The REF encourages universities to ensure that their research is used in the world beyond the academy by linking research impact to funding. 'Pull' mechanisms have focused on schools and teacher education. For example, the national survey of newly qualified teachers asks respondents how well their training has prepared them, 'to access educational research ... to assess the robustness of educational research [and] ... to understand and apply the findings from educational research' [3]. Similarly, England's Chartered College of Teaching argues that teachers' engagement with research should be viewed as the hallmark of an effective profession, and so positions research engagement as a part of what is required for individual teachers to achieve 'chartered' status. At the same time, 'Mediating' mechanisms enable the smooth transfer of research into practice. One such mechanism is 
the UK Funding Councils' 'Open Access' policy, which aims to make research reports freely available online [4]. Additionally, the Chartered College of Teaching provide its members with free access to the EBSCO research database and to the University of Bristol's Document Summary Service.

Universities in England have created formal or informal research liaisons with schools, partly in response to the government's promotion of evidence-informed practice. We found schools working with Manchester University, Cambridge University, Liverpool John Moores University, Sheffield Hallam University, University College, London (UCL), and Edge Hill University in the research described below; others undoubtedly exist. At the same time, the Department for Education has produced guidance to schools and universities, advising how such partnerships can be established. The latest guidance incorporates a change of direction: whereas a similar document that was published in 2015 [5] contained only one mention of universities, the latest document [6] includes case studies of six school-university partnerships (and one partnership in which schools partner with organisations other than universities). The guidance argues, 'Universities, independent schools and state-funded schools can all benefit from sharing their knowledge, experience and resources by working together' and it states that benefits could include better teaching, curriculum, and leadership. The published case studies include examples of university involvement in governance, sponsorship, sharing resources, and evaluation. However, there are only two references to research within these case studies: in one instance, a university is 'currently undertaking research to baseline all of the participating students' (i.e., school pupils) and, in another, there is said to be 'a vibrant partnership between the special school and the university's autism research centre' [6]. No further details are provided, for example, regarding what the participants in these partnerships actually do, so it is unclear as to how these case studies might point the way forwards for all schools to become better informed by research.

\section{Literature Review}

Furthermore, multiple barriers to schools' engagement with research have been reported in the literature about research utilisation. Whereas, some teachers are 'Definitive Supporters' of using research, others are 'Cautious Consumers', and others can be described as 'Critics' [7]. An American study found that many teachers were cynical, showing a distrust of research and resentment about being told to change their practice on the basis of research. The teachers who participated in this research spoke about a loss of control over their work and expressed either denial or defiance of research that was seen to be imposed by authority and expertise; they saw the imposition of 'research based practice' as manipulative and coercive [8].

Differences between individuals can depend on factors, such as role [9] and attitudes towards research [10]. Vanderlinde and van Braak [11] found that seniority made a difference: whereas classroom teachers reported feeling skeptical about the value of educational research, arguing that educational researchers handle too few questions of practical relevance, school leaders had a more moderate opinion about the gap, claiming to read educational research reports and incorporate the findings into their practice, 'especially findings with a possible impact on the school as an organisation' (p. 306). Similar findings were reported in Borg [12] and Everton et al. [13]. However, Beycioglu, Ozer, and Ugurlu [14], using a similar design to Everton et al. [13], found no significant differences between teachers with varying amounts of teaching experience; they also found no significant differences in the attitudes to research of men and women. A narrative review of the research literature found that few teachers read research, because most lack the time and the motivation to do so [15]. Those who do read research, tend to look for research that can be of practical benefit and they evaluate research with regard to their own values, beliefs, and experience; they also prefer easily-understood summaries or syntheses to research articles. However, there is some evidence that research can prompt teachers to consider their values, whether these are validated or challenged by the research that they read. Many teachers see research as necessarily quantitative but not all do so; there is a suggestion that the most valuable form of research is that which explains the link between what teachers do and what students learn. 
Another recent review of literature found that barriers to research use obtained at four levels: the 'research knowledge' level, the 'individual teacher' level, the 'school-organisational' level, and the 'communication' level [16]. At the 'research knowledge' level, teachers find it challenging 'to identify valid, relevant, and reliable information' from research, largely because they tend to value knowledge that can be immediately applied to their practice, and they do not find such information in research. At the 'individual teacher' level, teachers lack the skills that are necessary to interpret research findings and to apply them to their own contexts; they lack what has been called, 'research literacy'. There is also evidence to suggest that some teachers doubt whether research can, in principle, be applied to their practice. At the level of 'school-organisation', schools' cultures and structures are not well equipped to support teachers to engage with research. For example, schools provide little CPD (Continuous Professional Development), which might equip their teachers to use research and they provide little time for them to do so. Finally, the review identified few examples of communication between school teachers and researchers, although they found that many studies recommend school-university partnerships in order improve the conditions for research engagement. The review notes that questions about such partnerships remain, including 'how, with whom, and on what scale'.

In many countries, school-university partnerships are not a new concept, but they have existed for several decades, with a purpose and an agenda to educate student teachers (see, for example, Smedley 2001 [17] and Zeichner 2010 [18]). There is also literature regarding school teachers who undertake action research, supported by university researchers (see, for example, McLaughlin \& Black-Hawkins 2007 [19]). These studies demonstrate that school teachers and University faculty staff can productively work together, despite the many cultural differences between their organisations [20]. However, as van Schaik et al. (2018) recognize, questions remain about how school-university partnerships might enable schools to engage with research.

If it is true that schools and universities can benefit from, 'sharing their knowledge', as claimed [6], it would be helpful to know what sorts of links currently exist between schools and universities, and to consider how these links might enable such sharing. This paper uses the secondary analysis of data from five empirical studies to carry out an exploratory enquiry into this topic. The aim is to identify how schools are currently linked to universities and to explore the extent to which these links might lead to schools becoming better informed by research. The Research Question is, 'What activities enable school-university partnerships?' and the subsequent discussion coheres around the question, 'How might such partnerships enable school teachers to engage in research-informed practice?' In this article, 'research' is understood as defined by the Higher Education Funding Council for England, as 'a process of investigation leading to new insights, effectively shared'; it is to be judged on its originality, significance, and rigour. The term 'partnership' is used to include all aspects where schools and universities work together; this includes both formally-constituted partnerships with written agreements and more informal links, without such agreements.

\section{Methods}

This paper reports on a secondary analysis of data from five qualitative research projects, which were carried out by the research centre for Schools, Colleges and Teacher Education (SCaTE) at Edge Hill University, between 2013 and 2018 (see Table 1). The secondary analysis involves, 'reusing data created from previous research projects for new purposes' [21] —in this instance, to interrogate datasets in order to answer a new research question. Secondary analysis is usually carried out by researchers who are not involved in the original research; I was the sole researcher in the first-named project, co-researcher in the following three projects, and uninvolved in the final project. Between them, these projects involved individual interviews, with 94 teachers and school leaders in 58 schools or colleges, and participant observation of two teacher research groups (15 teachers). The individual projects have been published elsewhere [22,23] and they are also reported in a practitioner-facing book [24]. Each project had a slightly different focus: research use or dissemination or attitudes, by school leaders and/or teachers, in Primary and/or Secondary schools. Although none of these projects was specifically 
designed to investigate school-university partnerships, the partnerships were an aspect of all the projects, and each dataset included multiple references to school-university links.

Table 1. The school-based research projects that informed this paper.

\begin{tabular}{ccc}
\hline Title & Research Question \& Methods & Participants \\
\hline & RQ: How can educational research impact & \\
on Secondary school teachers and their & \\
teaching? 2 studies in Secondary Schools. & \\
& Participant observation of teachers' & \\
Using research to improve & research groups, discussing papers & 15 Secondary school teachers \\
provision for Gifted and Talented & about gifted and talented students. & of various subjects, including \\
pupils & Teachers planned and enacted & middle leaders. 2 Secondary \\
& participant inquiry to investigate and & schools, North (N.) England. \\
& improve their teaching of these students. & \\
& Data included written reports, & \\
& individual interviews at 3 points: & \\
& selection, mid-point, end. &
\end{tabular}

RQ: How can educational research impact on Primary school teachers and their teaching? Design included, (a) ascertaining what published research schools wanted, (b) sourcing and

Teachers' engagement with research: the perceptions of Primary School teachers providing appropriate research, (c) interviewing participants about the use of research. Individual or small group interviews at 2 points: (a) to discover what research was wanted and why, (b) to investigate teachers' use of research.
RQs: 1. Why might senior leaders encourage staff in their institutions to engage in/use research?

Attitudes of Senior Leaders to using research evidence

Teachers' engagement with research: the perceptions of research coordinators
2. How do senior leaders currently access research information? 3. What do senior leaders do to support teachers' engagement with research? Online survey, one-to-one, face-to-face, semi-structured interviews.
Joint project with staff from UCL \& Cambridge Universities. RQs: 1 . On what grounds do research coordinators select research for their school? 2. How do they expect teachers to use research? 3. What institutional or supra-institutional factors do they perceive as influencing their
3 Senior Leaders

(Headteachers or Deputies),

16 Class teachers, 4 TAs. 8

Primary schools, N. England. answers to the above questions? Individual interviews, stimulated by written statements (quotations from policy \& research documents).

RQ: How do School Leaders obtain and disseminate knowledge from research within their institutions? Focus groups; semi-structured, individual interviews with Senior and Middle leaders.
10 Headteachers or Deputy Headteachers, 10 Primary and Secondary schools, NW England.
Mobilising knowledge: how schools become research-informed
30 teachers in 26 schools, $\mathrm{N}$, S, E. England.

Approximately $40 \mathrm{~h}$ of transcribed data from all five projects were mined in order to provide information regarding school-university partnerships and to answer the research question posed above. The analytical methods involved a search for 'Key Words in Context' [25]. Previously-transcribed data were searched for key words-these included, 'university', 'uni', 'higher education', 'tutor(s)', and so 
on. Whenever a key word was found, the text around it was interrogated in order to establish whether the topic was related to school-university links, and whether these involved some form of research (universities were sometimes mentioned in a different context). If these conditions were met, the entire unit of conversation dealing with the topic was extracted for analysis. In some instances, this was a single sentence; in others, long sections of text. Each unit was then coded broadly, and then more finely; the intention was to gather, as accurately as possible, both the range and the detail of each unit of conversation.

\section{Findings}

\subsection{The Nature of the Partnerships}

All of the schools in these research studies had links with universities and also sometimes with other organisations. In most instances, the schools were linked to more than one university. Some of these links were short-term, lasting only for the duration of a single project, and some were longer term, lasting for several years. Typically, formal partnerships involved initial teacher education (ITE); these encouraged conversations between school and university staff, and other activities grew out of these conversations.

Within schools, research activity was generally coordinated by a teacher (usually designated 'research coordinator' or 'research lead'). In some schools, this person was at a senior level of the school's management structure, so research coordination was only one aspect of their role. In others, the research coordinator was a Middle Manager, reporting to a more senior leader. Research coordinators were expected to organise research-related activities within the school and sometimes they were also expected to oversee teacher research projects. In some instances, they were expected to liaise with universities and other organisations beyond the school.

The activities, overseen by research coordinators, are summarised in Table 2 and described in greater detail, as below.

Table 2. Activities undertaken in school-university partnerships.

\begin{tabular}{|c|c|c|}
\hline Type & The Role of the University & The Role of the School \\
\hline Postgraduate degrees & Provide degree programme & (part-) fund teachers \\
\hline Research projects & $\begin{array}{l}\text { Recruit teachers to be research } \\
\text { participants }\end{array}$ & Participate in research projects \\
\hline Evaluations & $\begin{array}{l}\text { Evaluate school-based innovative } \\
\text { projects }\end{array}$ & Plan and implement innovation \\
\hline $\begin{array}{l}\text { Teacher Research projects } \\
\text { (individual, group, school) }\end{array}$ & Supervise teachers & Fund teachers (sometimes in kind) \\
\hline $\begin{array}{l}\text { Research dissemination } \\
\text { conferences and seminars }\end{array}$ & $\begin{array}{c}\text { Organise conferences or seminar } \\
\text { series }\end{array}$ & Speak at conferences and seminars \\
\hline Initial teacher education & Varied roles, including assessment & Varied roles, including mentoring \\
\hline Research-informed CPD & Provide CPD & Hire university staff \\
\hline Bidding for funding & $\begin{array}{l}\text { Support schools in bidding for } \\
\text { research funds }\end{array}$ & Submit bid for funding \\
\hline
\end{tabular}

\subsection{Postgraduate Degrees}

Some schools supported teachers to undertake Higher Degrees at universities in order to develop a research-informed culture. From our interview data, it seemed that school leaders saw postgraduate study as helping to develop an ethos of professional enquiry within a school: 
The Masters project with Edge Hill [University], that was something to hang research on ... We have always got a number of people going through it, from different departments, starting those research conversations with their peers. (Headteacher, urban Secondary School)

It's phenomenal to see Masters students bumping into each other on the corridor and discussing ethics and identity within their classrooms, they are astounding. (Focus group member, urban Secondary School)

We've had a number of teachers undertaking Masters research. Over the last four or five years, we've had eight staff complete their Masters. That's worked really well because it's kick-started a bit of a research culture within the school, it has shown what is possible. (Research coordinator, Independent Secondary School)

These quotations describe some of the advantages of postgraduate study as a means for developing a research culture. Teachers who have a shared experience of postgraduate study might talk to each other, not only about these experiences, but also about their learning: they might have 'research conversations' and talk about 'ethics and identity within their classrooms' and thereby promote 'a bit of a research culture'. School Leaders recognize that, because Higher Degrees are sited at universities, they are subject to a quality control process, they are sited at universities; they have what the Independent School coordinator called 'academic clout'. Masters level accreditation is also a powerful incentive for many teachers; as one Secondary School research coordinator said, 'I think where teachers perhaps do research it's because they want to get an MA, or they want to get an MSc, or they want to get an MPhil'.

The ability to interrogate research findings and to make judgements about their usefulness for one's own practice, and then to assimilate this into practice, is a high level skill and not one that is developed to any significant level during teacher training. Those staff who undertake post-graduate qualifications usually develop this skill. Another advantage of staff undertaking post-graduate study was that study usually involves small scale research projects, which are related to practice. We found that these projects were sometimes tied to school improvement priorities and they often resulted in a development of practice for the individual involved.

Most of the schools that funded teachers to undertake post-graduate study did so for a small number of staff, partly because post-graduate study has significant cost implications. This means that only a few teachers could be supported in any one year and, when they completed their studies, there was no guarantee that they would stay at the school and thereby develop its research culture. However, one school recognised these limitations and took steps to increase the impact of post-graduate study:

We have an in-house Masters programme which fifteen of our staff are on, they come together once a fortnight and have a session with a university tutor or reading group based on previous or next session. This has given them the opportunity to see where their own experience sits with the research. This has gone extremely well and we are thinking of offering it wider next year in the school and across our teaching school alliance. (Assistant Headteacher, urban Secondary School)

This 'in-house masters programme' was arranged with a local university: the university agreed to provide some tutoring at the school site to support that group if a reasonably large number of teachers registered to do the Masters degree, thus benefitting both the teachers, who did not have to travel to the university for seminars, and the university, which gained more Masters students than they would otherwise have done. Although this arrangement was not common, it indicates one of the ways in which research engagement can potentially lead to a change in sufficient teachers to affect the culture of a school.

\subsection{Research Projects}

Several schools were involved in research projects that were generated and organised by a partner university. These were typically funded through the Educational Endowment Foundation (EEF), which 
funds research that involves several thousand schools in England. Two such projects, from a Primary and a Secondary school, were described in the following quotations. The first describes a 'knowledge transfer' project, funded by the EEF, in which both the university and the school received funding to support the school to engage with research, as provided by the university. The funding allowed the teachers to read research and ask, 'What can I learn from it?' The second quotation describes a project, which was organised by a university, to trial and evaluate a parental engagement programme.

The way we started was just saying, 'we know we need to look at reading', and looking at loads of different things. This was supported through the Institute of Education [at University College, London]. They brought us loads of different summaries of research and got us to theme them and sort them, and then look at the things that were really resonating with us, knowing our context ... [this prompted us to ask] 'What's going on? What are people saying out there? What things might I need to be prepared for and aware of? What new difficulties might be presented? There's this study here, that talks about using this model which is like we're doing now. What did they find? What were the benefits? What were the drawbacks? And what can I learn from their prior learning?' (Assistant Headteacher, urban Primary School)

The first big piece of research we did with a university was looking at children coming into our Year 7 with parents who had never really engaged in their education in primary schools ... to identify that cohort of children and to look at how we could involve them more in their education. So we had the children themselves and their parents, and sometimes we had special events that they came to, and after a year, we are still tracking those children through school. Not every parent had been to everything, but every parent had been to something and we interrogated the children ... they were very different [as a result of the research]. (Principal, urban Secondary School)

These quotations emphasised different types of engagement in research. The first emphasised how teachers learnt from research, chiefly from reading and discussion research. The second emphasised the practical aspect of research - the organisation of events for children and parents, and the monitoring of the effects of these events. This distinction is about engaging with research and engaging in research [26]. These two types of engagement provide different benefits for teachers: engaging with research can provide a theoretical understanding of practice; and engaging in research can enable practice to be interrogated according to a reasonably robust methodology. Nevertheless, engagement in a university's research project was not always seen as beneficial. Indeed, in some cases in our data, it seemed that the teachers viewed their school's involvement in such a project as burdensome, rather than an opportunity to learn from research.

\subsection{Evaluations}

One particular type of research project is the evaluation. Evaluations appear to be uncommon in schools, but the research centre for Schools, Colleges and Teacher Education was involved in several examples. One of these took place in a Primary School in a deprived area of an industrial town in the North of England, as part of the Perceptions of Primary School Teachers project. The teaching staff were concerned that many of the children had very poor vocabulary and they appeared not to know some basic words. Together, they designed an intervention that they called Talk for Learning. This involved every child having a weekly, 15-minute oracy session in small groups, which was organized by a Teaching Assistant.

Our evaluation involved interviews with teachers and school leaders, to establish what they were doing and why. We also undertook non-participation observations of training events for staff, and observations of the oracy sessions on three occasions: once near the start of an academic year, once at around the mid point, and once near the end. In addition, we carried out a brief review of the research 
literature, to establish that there was support for the belief that regular, short oracy sessions would benefit children's vocabulary acquisition, which would, in turn, benefit their reading and writing.

The review established that there were firm grounds for the project. Interviews further established that the teachers and teaching assistants understood what they were required to do and why, and they were universally enthusiastic about the aims of the project. The first set of observations found that the children participated well, talked reasonably fluently within the sessions, and appeared to use age-appropriate vocabulary.

The mid-point observations were much less positive. We found that the Teaching Assistants were relying on a limited repertoire of ideas for the sessions, were less enthusiastic about them, and less clear about what they were trying to achieve for their children. Brief interviews at this stage confirmed that they were unclear as to whether the children were actually making progress. They agreed that the sessions were repetitive, and had lost confidence in their ability to motivate the children. At this point, we reported to the Headteacher and recommended further training in order, a) to give the Teaching Assistants new ideas for sessions and $b$ ) to enable them to explore the purpose of the sessions. This recommendation was agreed, and the final set of observations found that the enthusiasm and engagement of pupils and Teaching Assistants had resulted in markedly better quality of talk: children gave longer answers than previously, listened to each other more, and maintained a focus over the duration of the session.

This evaluation, and other similar evaluations, gave schools an independent means of considering the strengths and weaknesses of specific projects. It enabled school leaders to appropriately direct resources and to manage the project better, to achieve its aims. Moreover, teachers and school leaders were able to challenge the evaluations, including the basis on which evaluative statements were made, and the evidence for this basis. Perhaps, because teachers in each school had selected a focus for their evaluation, and the evaluation concerned their own school, they engaged with both the process and the product of the evaluation, and committed to making changes in their practice (achieved, for example, through further training).

\subsection{Teacher Research Projects}

Several schools funded teachers to undertake Teacher Research projects. For instance,

I did say that if people wanted to do a bit of action research, and I was quite keen to develop this, that if it was finished and if it was published, then I would give them $£ 500$ because I think it is important to value what people are doing. It's not a big amount of money ... I don't actually think that anyone did it for the money but it was a nice way of having a little bit extra for the extra paper that they had to write ... I also think if people started something it made them more likely to see it through, they know they'd put their name forward, they knew I'd done that and I think for value for money, it was amazing value for money, not just in terms of what they found out but how it affected them as a person. (Principal, urban Secondary School)

In some schools, such projects were organised and entirely supported within the school. In others, Teacher Researchers were supported by university researchers:

[Name] would come in and do little research methods, lunch time seminars, on how to do a questionnaire or, how to do interviews and she'd give some academic background to the pros and cons of different research instruments, so, that kind of thing was very helpful and she would leave us with the PowerPoint so that someone with a bit of knowledge, like the research coordinator, could then use that resource. (Deputy Headteacher, rural Secondary School)

Interviewees mentioned two particular advantages of university support for Teacher Research. The first is that university tutors have almost invariably undertaken research themselves; they understand 
how to undertake research. This is not necessarily the case with Teacher Research that is solely supported within the school. The second is that Teacher Researchers who are supported by university tutors are able to discuss matters with these tutors and their fellow students. Again, this is not necessarily the case with all Teacher Research projects.

However, the funded Teacher Research was spoken of as something that had happened in the past, rather than something that continued unabated. In England, various government-funded initiatives during the 1990's and 2000s had supported teachers to undertake small-scale research projects, for instance, as part of a Master's degree, but this funding had ceased with the introduction of the national austerity policy in 2010 [27]. Consequently, most of the Teacher Research reported in our data was not supported by universities, and it might have lacked both methodological rigour, and the requirement (normal to most academic research) of building their research on the basis of previous research.

\subsection{Research Dissemination Conferences and Seminars}

Most research coordinators arranged some form of research dissemination events for teachers. Usually, these took place on site. For example, in one Further Education college, one Staff Development day every year was spent as a whole-college conference. This included a keynote address from a visiting speaker, and those staff who had engaged in research during the year presented their work to their colleagues in parallel sessions. Staff from neighbouring schools and universities were also invited to attend. Another school organised an after-school, monthly research seminar series, at which a range of speakers, mostly from universities, spoke about their work and its implications for schools. Such events hold potential for teachers to engage with research and so to learn about research; they also allowed the dissemination of Teacher Research, but they were seen as individual, 'stand alone' occasions, without necessarily implying long-term development.

\subsection{Initial Teacher Education (ITE)}

All of the schools in our research were in partnership with universities in relation to ITE, although the respective roles of the schools and universities varied. In some partnerships, universities were heavily involved; student teachers undertook substantial periods of their courses at the university and university tutors visited the schools several times per year. In others, the role of university staff was largely confined to confirming the assessments of school leaders: university staff visited the schools only once or twice per year and appeared to have a largely administrative function.

Involvement in ITE enabled some teachers and school leaders to share their knowledge regarding research with student teachers. In doing so, they sometimes deepened their own understanding of both teaching and research. For example,

Often, a piece of advice to trainee teachers is, 'You need to develop your questioning'. But when we start to read the research, it can crystalise that a little bit better. So somebody might be able to say, 'I asked this particular type of question and then I had that dialogue because I was working off this document that I'd read, which talked about these different types of questions, and I wanted to try it out'. (Assistant Vice Principal, urban Secondary School)

Involvement in ITE also allowed the teachers to experiment with new approaches to teaching. For example, the following teacher explained how student teachers worked in triads, in a way that was informed by Lesson Study [28]:

We feel very strongly about fostering new talent. In the maths department we had fifteen PGCE (Post-Graduate Certificate in Education) students and it was fabulous working in threes where one would teach, one observes and one would support. It was incredibly efficient; the quality of the planning and lessons was phenomenal. (Focus group, Secondary)

Such examples provide reasons for teachers to engage with research: a knowledge of research can inform teacher training. However, our data also contained examples of teachers' erroneous beliefs 
about teaching and it is possible that, when they believed that they were imparting knowledge that was acquired from research, these teachers were actually imparting mistaken beliefs and possibly even disinformation.

\subsection{Research-Informed CPD}

Several research coordinators claimed that research informed their school's programme of Continuous Professional Development (CPD). The fullest example described support from the Centre for the Use of Research Evidence in Education (CUREE):

We identify from the school development plan what the key issues are for the school for that year. So, for example, we've been looking at stretch and challenge for the last 2 years, particularly in light of the deeper level of questioning that the new GCSE and A-levels will be bringing about. And then we commission CUREE to find us some research based on what it is that we are interested in doing. We've bought a route map from CUREE ... [every year] for three years. So what we get is an absolutely bespoke interactive route map, and on there, there are larger pieces of research, but there are also lots of smaller pieces of research, two sides of A4 which have been summarised with links for further reading so they are manageable for staff to be able to dip into and then if it sparks an interest they've got the resource to go further. So it cuts out that huge volume of stuff that's out there that staff do not have time to go and look at and because we go through CUREE we actually know that what they are reading is actually a valuable piece of research it's not something that they have picked up on some blog... And then we actually work with the staff, we've got a learning and teaching group, they look at the route map ... they look at aspects of that that are applicable to their department. (Deputy Head, Secondary School)

This quotation sums up some of the advantages of outsourcing the search for research information: the information that is provided by experts can be trustworthy, concise, and tailored to the requirements of the school (although this comes at a financial cost). Together with the example from University College, London, as cited above, this quotation gives the clearest example in the data of teachers engaging systematically with research. It is also notable that CUREE is a small independent company that receives no regular public funding; this suggests that encouraging schools to engage with research can, at least in some circumstances, be a profitable venture.

\subsection{Bidding for Funding}

One school in our research had worked with university staff to bid for research funding from the EEF, although this was not much discussed, which was possibly because of commercial sensitivities. Bidding appears to be an underused form of partnership activity and there might be more opportunities for joint research bids than are commonly realized.

\subsection{Benefits to Schools}

Research coordinators described several benefits of working with universities. These included:

- Access to research databases and sometimes guidance on how to utilise these

- Universities undertaking literature reviews for schools, finding high quality research to support staff in undertaking practitioner research

- Access to university-level teaching (e.g., in Postgraduate programmes)

- University tutors helping to develop the research literacy skills of school staff

- Opportunities for joint research projects and authoring of research papers and reports

Different teachers gave different reasons for external partnerships. For example: It's about making links outside of school because you can exhaust what's within school. You need 
a fresh perspective and external verification is quite important. (Assistant Head Teacher, suburban Secondary School)

We've got the will in the schools but we don't have the know-how, and the know-how is coming from the universities, so we talk to them to bridge that gulf. We've got the researchers at the universities who have been doing this for years. They might not have an understanding of the educational context in schools but they support the lead researcher in the school. (Executive Principal, Multi-Academy Trust)

However, there was also evidence that teachers and school leaders have an ambivalent relationship with universities. On the one hand, they appear to value the expertise that school-university partnerships can provide, and the prestige that can be gained through partnerships with universities. On the other hand, teachers contribute to a discourse that positions universities as being detached from the realities of life in schools, and therefore having little to offer to them. This ambivalence is captured in our data:

Sometimes, I've been [reading] research that the academics at universities have done, 'I don't think you've even tested this in a real classroom' because, quite often, theory can look pretty good and ... when they try to apply that theory, it just isn't practical. (Research coordinator, International School)

I can understand that if you're a researcher and you've got a hypothesis, you conduct your research to justify your hypothesis, but as teachers, we're not researchers, so our core business is about pupils being happy, achieving well and leaving school as rounded individuals. So I think for us, the research has to be about something that is benefitting the learning for the students. (Deputy Head, teaching and learning, Secondary School)

There is a professor ... who's written all the 'Thinking for schools' books ... I was lucky enough to do some work with him at Newcastle University, so he was happy to come and work with people in school on that. So you've got really high calibre people who know what they're talking about, setting the foundations of what you're doing. (Research coordinator, Secondary School)

From some perspectives, university tutors seem out of touch with the reality of schools; they can seem to deal in 'theory' that 'just isn't practical' and they can appear interested only in justifying hypotheses. At the same time, universities employ 'high calibre people who know what they're talking about'. Our interview data have contained views that are strongly positive; others have been strongly negative; it depends who we talk to.

\section{Discussion}

The research reported here had limitations. The schools were not randomly selected and the interviewees were not necessarily representative of teachers in England or, indeed, of the UK as a whole. They represent a snapshot of school-university partnerships (broadly conceived) in one jurisdiction, at a particular point in time, in a shifting policy landscape; they are not necessarily generalisable to other times or jurisdictions. Instead, they reveal some of the opportunities and challenges that can confront attempts to bridge the research-practice gap through school-university links.

In summary, we have found that school-university partnerships are formed around activities, including postgraduate degrees, research projects and evaluations, Teacher Research projects, research dissemination conferences and seminars, Initial Teacher Education, research-informed CPD, and, in a few instances, bidding for funding. Superficially, the length of this list might suggest that schools and universities in England are successfully forming partnerships that can lead to evidence-informed practice. In principle, each of these activities can promote dialogue between researchers and teachers, 
and they hence increase the quality and quantity of evidence-informed practice in schools. Furthermore, they can benefit both parties; they enable universities to attract students to postgraduate degrees and to disseminate their research and create accounts of 'research impact'. They also enable teachers to develop their practice through postgraduate degrees and CPD, and to experiment with new ideas and evaluate them reasonably thoroughly through evaluations and Teacher Research. Some activities (including postgraduate degrees, research dissemination conferences and Initial Teacher Education) enable teachers to engage primarily with research, whilst others (including research projects and Teacher Research projects) enable teachers to engage primarily in research. Some activities enable both.

However, the school-university links that we have investigated fall somewhat short of the policy aspiration for 'sustainable and reciprocal partnerships' [6]. For the most part, the schools in our research had quite loose relationships with their partner universities. Often, these relationships were formed around Initial Teacher Education, with other activities occurring largely as a result of ITE. These other activities were usually single projects, with little expectation that they would last beyond the life of a single project. The schools seemed to prefer to 'shop around' for their university partners, being involved in several liaisons, but not necessarily committing to any one; their relationships with universities were more 'polygamous' than 'monogamous'. Indeed, across our data as a whole, it seemed that blogs and social media were cited as frequently as universities, as sources of research information. For their part, it seems that universities have a firm commitment to the ITE aspect of partnerships, but not necessarily to other activities, which tended to rely on one or two individual lecturers, usually with a background in schoolteaching, and a particular enthusiasm for working with schools.

In this context, the Department for Education's guidance, Setting up school partnerships, with its recommendations for formal agreements between the partners, is likely to be ineffective at the present time. Although there are reciprocal benefits to be gained from school-university liaisons, they are not particularly strong. Schools can develop their teaching staff through postgraduate degrees and $\mathrm{CPD}$, but they can choose to do this through other organisations instead. Enthusiasm for evaluations and Teacher Research was not very strong in our data: evaluations occurred very infrequently and Teacher Research had largely ceased. Significantly, the role of universities in ITE has continued to fall, with many routes into teaching being either entirely, or almost entirely, led by schools [29]. This is particularly problematic for research partnerships, because research and development is 'most heavily embedded within school-led initial teacher training' [30]. For their part, universities can benefit from partnerships with schools by attracting school teachers to postgraduate degrees, but these degrees are expensive and, since 2010, when the aspiration for all the teachers in England to have a Masters degree was abandoned, the number of teachers on such programmes has fallen [27]. Although school-university partnerships offer universities opportunities to disseminate their research and create stories of 'impact', such an impact is rated less highly in the Research Excellence Framework (REF) than other means, such as influencing policy or resources [31]. Therefore, although there is evidence that school-university partnerships can benefit evidence-based practice, there is also evidence that school-university links are founded on activities that are declining, those that are short-term, and those that heavily rely on the enthusiasm of a few people.

In this situation, recommendations for schools and universities to enter into formal partnership agreements are necessary but insufficient to ensure more research-informed practice. At least three things are necessary for this to occur.

First, partnership agreements should enable teachers to engage both in and with research, so that, whatever activities the partnership engages in, research-based ideas can be critically scrutinised, systematically trialled, and rigorously evaluated by teachers in schools. For teachers, engaging with research can suggest new solutions to problems, whilst engaging in research allows for these solutions to be tested with a degree of methodological rigour (alternatively, if teachers engage only with research, their practice might not be changed by the research-based ideas that they encounter; if they engage only in research, they might spend considerable effort finding out what is already known). There is 
no evidence in our data that schools and universities structure their joint activity so as to ensure that teachers can engage both in and with research; schools would likely become more research-informed if this were done systematically.

Second, universities will need more incentives than hitherto, to form research partnerships with schools. The way in which 'research impact' is currently measured in the REF encourages universities to demonstrate that their research has benefitted large numbers of people, however superficially [31]. Embedding research-informed practice in schools will require fewer, deeper engagements with research, and this will need to be recognised in the relevant assessments of research impact.

Finally, schools should be encouraged to form 'monogamous' relationships with universities. School-university partnerships should operate for longer than a single year and that the benefits to both parties should be clearly specified, monitored, and evaluated. Particular thought should be given to the issue of funding to ensure that partnerships can be prioritised by both parties, and to leadership, so that the success of research engagement does not rely on the commitment of a small number of people in individual schools and universities. In this way, the potential for school-university partnerships to generate research-informed practice in schools might finally be realised.

Funding: This research received no external funding.

Acknowledgments: I would like to thank my co-researchers in the projects, listed above: Susan Graves, Chris Brown, Sue Brindley, Gary Jones and Fran Riga.

Conflicts of Interest: The author declares no conflict of interest.

\section{References}

1. Tripney, J.; Kenny, C.; Gough, D. Enabling the use of research evidence within educational policymaking in Europe: Lessons from the EIPEE project. Eur. Educ. 2014, 46, 55-74. [CrossRef]

2. Higher Education Funding Council. Assessment Framework and Guidance on Submissions; HEFCE: Bristol, UK, 2011.

3. Gov.uk. Newly Qualified Teachers: Annual Survey. 2014. Available online: http:/www.gov.uk/government/ collections/newly-qualified-teachers-annual-survey (accessed on 30 September 2016).

4. Research Councils UK. RCUK Policy on Open Access and Supporting Guidance. 2013. Available online: http://www.rcuk.ac.uk/documents/rcukopenaccesspolicy-pdf (accessed on 30 September 2016).

5. Department for Education. Effective School Partnerships and Collaboration for School Improvement: A Review of the Evidence; DfE: London, UK, 2015.

6. Department for Education. Setting up School Partnerships; DfE: London, UK, 2018.

7. Jones, M.L. A study of novice special educators' views of evidence-based practices. Teach. Educ. Spec. Educ. J. Teach. Educ. Div. Counc. Except. Child. 2009, 32, 101-120. [CrossRef]

8. Nicholson-Goodman, J.; Garman, N.B. Mapping practitioner perceptions of 'It's research based': Scientific discourse, speech acts and the use and abuse of research. Int. J. Leadersh. Educ. 2007, 10, 283-299. [CrossRef]

9. Ion, G.; Iucu, R. Professionals' perceptions about the use of research in educational practice. Eur. J. High. Educ. 2014, 4, 334-347. [CrossRef]

10. Lysenko, L.V.; Abrami, P.C.; Bernard, R.M.; Dagenais CJanosz, M. Educational research in educational practice: Predictors of use. Can. J. Educ. Rev. Can. L'éducation 2014, 37, 1-26.

11. Vanderlinde, R.; van Braak, J. The gap between educational research and practice: Views of teachers, school leaders, intermediaries and researchers. Br. Educ. Res. J. 2010, 36, 299-316. [CrossRef]

12. Borg, S. English language teachers' conceptions of research. Appl. Linguist. 2009, 30, 358-388. [CrossRef]

13. Everton, T.; Galton, M.; Pell, T. Teachers' perspectives on educational research: Knowledge and context. J. Educ. Teach. Int. Res. Pedagog. 2000, 26, 167-182. [CrossRef]

14. Beycioglu, K.; Ozer, N.; Ugurlu, C.T. Teachers' views on educational research. Teach. Teach. Educ. 2010, 26, 1088-1093. [CrossRef]

15. Cain, T. Research utilisation and the struggle for the teacher's soul: A narrative review. Eur. J. Teach. Educ. 2016, 39, 616-629. [CrossRef] 
16. Van Schaik, P.; Volman, M.; Admiraal, W.; Schenke, W. Barriers and conditions for teachers' utilisation of academic knowledge. Int. J. Educ. Res. 2018, 90, 50-63. [CrossRef]

17. Smedley, L. Impediments to partnership: A literature review of school-university links. Teach. Teach. 2001, 7, 189-209. [CrossRef]

18. Zeichner, K. Rethinking the connections between campus courses and field experiences in college- and university-based teacher education. J. Teach. Educ. 2010, 61, 89-99. [CrossRef]

19. McLaughlin, C.; Black-Hawkins, K. School-university partnerships for educational research-distinctions, dilemmas and challenges. Curric. J. 2007, 18, 327-341. [CrossRef]

20. Nutley, S.M.; Walter, I.; Davies, H.T. Using Evidence: How Research Can Inform Public Services; Policy Press: Bristol, UK, 2007.

21. Bishop, L. Secondary analysis of qualitative data. In Qualitative Research; Silverman, D., Ed.; Sage: London, UK, 2016.

22. Cain, T. Teachers' engagement with published research: Addressing the knowledge problem. Curric. J. 2015, 26, 488-509. [CrossRef]

23. Cain, T. Teachers' engagement with research texts: Beyond instrumental, conceptual or strategic use. J. Educ. Teach. 2015, 41, 478-492. [CrossRef]

24. Cain, T. Becoming a Research-Informed School: Why? What? How? Routledge: London, UK, 2019.

25. Wegerif, R.; Mercer, N.; Dawes, L. From social interaction to individual reasoning: An empirical investigation of a possible socio-cultural model of cognitive development. Learn. Instr. 1999, 9, 493-516. [CrossRef]

26. Cordingley, P. The contribution of research to teachers' professional learning and development. Oxf. Rev. Educ. 2015, 41, 234-252. [CrossRef]

27. Chung, J.; Atkin, C.; Moore, J. The rise and fall of the MTL: An example of European policy borrowing. Eur. J. Teach. Educ. 2012, 35, 259-274. [CrossRef]

28. Allan, D.; Boorman, D.; O'Doherty, E.; Smalley, P. Lesson study. In Becoming a Research-Informed School: Why? What? How? Cain, T., Ed.; Routledge: London, UK, 2019; pp. 159-176.

29. Department for Education. Teacher Training Courses. 2018. Available online: https:/getintoteaching. education.gov.uk/explore-my-options/postgraduate-teacher-training-courses/teacher-training-courses (accessed on 12 February 2019).

30. Walker, M. Insights into the Role of Research and Development in Teaching Schools; National Foundation for Educational Research: Slough, UK, 2017.

31. Cain, T.; Allan, D. The invisible impact of educational research. Oxf. Rev. Educ. 2017, 43, 718-732. [CrossRef] 